is, from the time the call was made) from those transported by the routine ambulance service. The predictable difference in overall mortality has never been used as evidence of the salutary effect of prehospital coronary care. Results obtained with the Belfast mobile coronary care unit (MCCU) indicate that the outlook of patients seen and treated early (mortality $\left.10^{\circ}{ }_{0}\right)^{2}$ is better than that of patients admitted to hospital coronary care units at a time of lower risk by traditional means (hospital mortality $15-20^{\circ}$ ) and much better than that of patients seen early but not given intensive care (mortality $26 \%$ ). ${ }^{3}$

Of course the existence of an MCCU by itself cannot prevent many of those deaths which occur within the first minutes of an attack. Where an MCCU is available, however, much more can be done, through the establishment of "satellite" units in densely populated factories and office blocks ${ }^{4}$ and the training of large numbers of paramedical personnel in the technique of resuscitation, ${ }^{5}$ to prevent early death from ventricular fibrillation.

Dr Hampton found that more lives might have been saved had the "cardiac ambulance" been dispatched more often while it was available. The criteria for selection of calls from the public are crucial. With a short response time for the special ambulance we would question the logic of sending a routine ambulance following a 999 call if it was nearer the patient. Dr Hampton's report does not question the unassailable fact that the principal causes of death-ventricular fibrillation and extension of the infarct due to autonomic disturbance-are mainly operative outside hospital. Since the means of preventing death are available and relatively inexpensive the logic of providing prehospital coronary care is irrefutable. Much the same argument could be used to justify the continuation of the fire service were it under attack.

Direct measurement of the impact on community mortality cannot be made entirely from the results of operation of an MCCU. Nevertheless, an estimate can be made, ${ }^{6}$ and a decline in community mortality coinciding with the inception of an MCCU has been observed.?

J S GEDDES Royal Victoria Hospital,

A A J ADGEY

Belfast

Working Party of the Royal College of Physicians and the British Cardiac Society, Journa

2 Pantridge, J F, Quarterly fournal of Medicine, 1970

39, 621.
Mather, H G, et al, British Medical fournal, 1971, 3, 334.

Grace, W J, in Coronary Care: Pre-hospital Care of
Acute Myocardial Infarction. New York, American Heart Association, 1973.

${ }^{5}$ Cobb, L A, and Alvarez, H, III, National Conference on Standards for Cardiopulmonary Resuscitation $(C P R)$ and Emergency Cardiac Care $(E C C)$. Washington, DC, National Research

- Pantridge, J F, et al, The Acute Coronary Attack. Tunbridge Wells, Pitman Medical, 1975.

Crampton, R S, et al, American Journal of Medicine, $1975,58,151$.

\section{Sigmoid volvulus in Africa}

SIR,-The article by Mr H G Sturzaker and others (8 November, p 338) about recurrent sigmoid volvulus touched on a subject of interest to readers in Africa, where this condition is a frequent cause of lower intestinal obstruction. It is generally accepted that two different varieties of sigmoid volvulus occur here, an acute fulminating and a slowly pro- gressive, subacute form, each with its own specific clinical and pathological characteristics. ${ }^{1}$

The case histories reported by Mr Sturzaker and his colleagues suggest that all their patients suffered from the subacute type, but other findings are not consistent with it. Most of the attacks described ended spontaneously, while all patients here need at least decompression with a flatus tube passed through a sigmoidoscope, if not a laparotomy. Also the sex ratio is the reverse of that seen in Britain. Subacute volvulus is even rare in women; if the patient presenting with a volvulus is a woman this is a strong argument against attempting conservative treatment." And last of all, the gross pathology is quite different from that shown in the photograph accompanying the article. Two cases with muscular hypertrophy were found in the series reported, whereas subacute cases in Africa, besides the white striae of the mesocolon, invariably show loss of haustrations and taeniae spread out as a continuous muscular coat.

Because of these differences it remains an open question whether we have to do with the same disease.

Mpwapwa District Hospital, Mpwapwa ' Davey, w W, Companion to Surgery in Africa, p 235.
Edinburgh, Livingstone, 1968.
' Shepherd, J J, Tropical Doctor, 1971, 1, 174.

\section{Infections after splenectomy in Hodgkin's} disease

J J MEUzelaAR

SIR,-The paper by Dr B W Hancock and others (7 February, p 313) draws attention to the severe infection which may occasionally follow splenectomy. King and Shumaker first reported on this in 1952, ${ }^{1}$ and several groups have confirmed their findings since then. The pattern of abrupt onset and a rapid fulminating course is borne out by the experience of $\mathrm{Dr}$ Hancock and his colleagues, but the usual infection with pneumococci, Neisseria meningitidis, or Haemophilus influenzae was seen in only one of their patients.

The reason for the increased susceptibility to infection in splenectomised patients is not known. A fall in IgM levels following splenectomy has been described previously. ${ }^{2}$ Other immunoglobulins are unaffected. The antibody response in splenectomised patients to immunisation subcutaneously is normal, ${ }^{3}$ but with intravenous immunisation ${ }^{4}$ it is feeble and delayed. This may play a role in their liability to septicaemia. Little evidence is provided by Dr Hancock and his colleagues that cell-mediated immunity is affected by splenectomy, and in a previous study none was found. ${ }^{8}$

The susceptibility to infection in such patients with Hodgkin's disease will be complicated by the immunosuppressive and myelosuppressive effects of treatment by radiotherapy or cytotoxic drugs and the effect of the disease itself. It has been suggested, and is our experience to date, that splenectomised patients with Hodgkin's disease are better able to tolerate radiotherapy ${ }^{6}$ and cytotoxic therapy. ${ }^{7}$ Blood leucocyte and platelet counts may give a false sense of security in these patients, and greater bone marrow damage could follow their more vigorous therapy. The patients of Dr Hancock and his colleagues were reported to be leucopenic, but we are not told how vigorous a leucocytosis they were able to mount in the face of their overwhelming infection or indeed the severity of the leucopenia.

The crux of their paper is whether the increased susceptibility to infection justifies splenectomy in patients with Hodgkin's disease. To make a judgment we have to know what risks are involved. The value of splenectomy in detecting disease in the spleen and facilitating comprehensive therapy is established. ${ }^{8} 9$ The underlying disease influences the incidence of infection in splenectomised patients. In Hodgkin's disease the incidence of serious infection has been reported at $1.4 \%$ with a mortality of $0.5 \%$ from a survey of 1170 splenectomised patients. ${ }^{10}$ Surprisingly, this is a lower incidence than seen in patients splenectomised for nonmalignant conditions. Predisposing factors in reported cases are youth and exposure to quadruple chemotherapy.

The improved survival with better staging and treatment probably outweighs the risk of infection. When improved techniques for detecting and treating splenic disease are available the problem will be resolved. In the meantime it is necessary to identify groups in whom it is safe not to perform splenectomy and to take into account the special susceptibility of children. As severe infection occurs predominantly within two years of splenectomy careful surveillance is called for, particularly as most patients will be receiving radiotherapy or cytotoxic drugs during that time. It has also been suggested that children should be given penicillin cover during the period at risk. ${ }^{11}$

P AMLot

J R TROUNCE

Medical Oncology Unit,

Guy's Hospital,

London SE

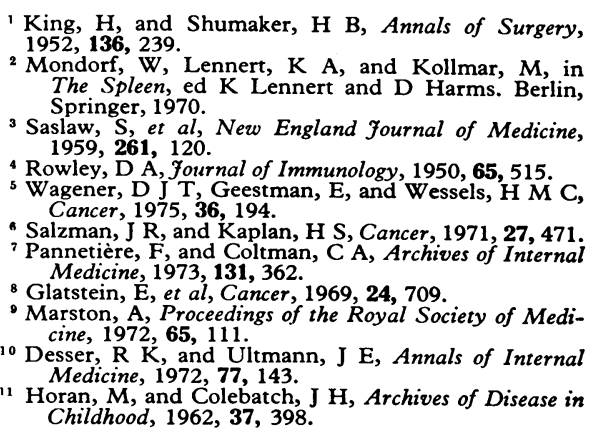

Childhood, 1962, 37, 398 .

\section{Selective induction of labour}

SIR,-Dr P W Howie and his colleagues (17 January, $p$ 150) express doubt as to the validity of the results of Professor K O'Driscoll's prospective study of 1000 primigravidae in which the induction rate was $9.5 \%$ and caesarean section rate $5.1 \%$. The Glasgow group question if any disadvantages arise from induction of labour and infer that such a policy will result in a reduction of caesarean sections. This is a surprising statement when in their own study ${ }^{1}$ of elective induction in 228 healthy pregnant women selected at 38 weeks' gestation $67.5 \%$ of the total were induced and $6.1 \%$ required caesarean section. This is a high caesarean section rate for such patients and Dr Howie might like to compare the annual rate of induction and incidence of operative deliveries at the Glasgow Royal 
Maternity Hospital over the past five years with that at the National Maternity Hospital in Dublin, which was as shown in the table.

\begin{tabular}{|c|c|c|c|c|c|}
\hline & 1970 & 1971 & 1972 & 1973 & 1974 \\
\hline $\begin{array}{l}\text { No of Deliveries } \\
\text { Induction }(\%) . . \\
\text { Caesarean }\end{array}$ & $\begin{array}{l}6255 \\
36 \cdot 0\end{array}$ & $\begin{array}{l}7083 \\
31 \cdot 0\end{array}$ & $\begin{array}{l}7252 \\
25 \cdot 9\end{array}$ & $\begin{array}{r}7315 \\
27 \cdot 4\end{array}$ & $\begin{array}{l}7676 \\
21 \cdot 2\end{array}$ \\
\hline $\begin{array}{c}\text { section rate }(\%) \\
\text { Forceps rate }(\%)\end{array}$ & $\begin{array}{l}4 \cdot 2 \\
7 \cdot 7\end{array}$ & $\begin{array}{l}5.0 \\
9.5\end{array}$ & $\begin{array}{l}5.3 \\
8.8\end{array}$ & $\begin{array}{l}5.3 \\
9.3\end{array}$ & $\begin{array}{r}5.0 \\
10.5\end{array}$ \\
\hline
\end{tabular}

In Oxford, because of evidence in our annual reports of a steady rise from 1970 in the numbers of mothers requiring delivery by caesarean section, we carried out a retrospective analysis from 1968 to $1974 .^{2}$ The induction rate increased steadily from $32 \%$ in 1968 to $55 \%$ in 1974 . The caesarean section rate, which had fallen from $8.3 \%$ in 1968 to $6.2 \%$ in 1970 , then rose progressively, to reach $10.3 \%$ in 1974 . Analysis of the caesarean sections showed that the rise was due almost entirely to an increase in the number of emergency operations. The diagnosis of fetal distress in labour induced by amniotomy and immediate oxytocin was the main reason for the increased caesarean sections. In the light of this and other evidence a more conservative policy has been adopted in Oxford.

Induction of labour for sound obstetric reasons and acceleration of a slow labour are undisputed. Elective induction in normal pregnancy can be justified only if there are no significant fetal or maternal complications associated with this approach. Our experience suggests that a major disadvantage of a high rate of induction using oxytocin stimulation will be an increased incidence of caesarean section. In large maternity hospitals the low risk of natural childbirth should not be forgotten and healthy pregnant women should be given every encouragement and support to experience normal labour and delivery. The practice of intervention in such pregnancies cannot be expected to improve the results in terms of fetal and maternal health.

JOHN BONNAR

\author{
University Department of Obstetric \\ and Gynaecology, \\ Cool \\ Rotunda Hospital,
}

\footnotetext{
' Cole, R A, Howie, P W, and MacNaughton, M C Bonnar, J, Thornton, C, and Subramaniam, S, to be published.
}

\title{
Coitus and coronaries
}

SIR,-I read with interest your leading article (21 February, $p$ 414) on this subject. In my past experience of 12 years of busy general practice in the West End of London I was urgently called out by certain professional ladies in Mayfair to attend only two sudden deaths. Both were due to myocardial infarction in elderly men, later confirmed by necropsy. One death occurred during coitus, while the other man died during precoital dalliance when photographic and mild physical stimuli were being administered. Both these events took place in prostitutes' flats in the late afternoon.

In view of the very thriving local industry of providing sexual services of every kind, I regard this incidence of two sudden deaths as being remarkably low.

J B VERgano

\section{Compulsory vocational training}

SIR,-I heartily endorse the views of Dr B M Goss (28 February, $p$ 527) regarding the present precipitate rush towards compulsory vocational training for general practice.

In the past many young graduates have spent a number of years working in a hospital specialty and gained relevant higher qualifications before eventually deciding to enter general practice. A glance through the pages of the Medical Directory will confirm the range and variety of qualifications and interests gained in hospital medicine by doctors who have subsequently become general practitioners. Not only has the hospital service gained committed middle-grade junior staff but their experience and clinical expertise have in due course undoubtedly enriched their practice of family medicine.

Should the present proposals for such rigid entry requirements for general practice be adopted I fear such doctors will have a strong disincentive to enter general practice in Britain because of the extra training involved. Should they, for financial, family, or other reasons, decide to leave hospital medicine they will have little choice but to practise abroad in those parts of the world where it is more easily possible to combine family medicine with a specialty interest.

Few newly qualified doctors would wish to commit themselves irrevocably to a chosen specialty immediately following registration and few would wish them to do so. We have been fortunate in Britain that it has been possible to approach one's eventual chosen specialty (including general practice) along several different paths. Today the rapidly evolving nature of medicine makes it more important than ever that we retain flexibility in our medical careers.

It is therefore hoped that lack of Parliamentary time, if not lack of finance, will result in the indefinite postponement of these ill-considered and unnecessary proposals. In the meantime all who are concerned at this increasing trend towards more rigid compartmentalisation within medicine would do well to follow Dr Goss's advice and ensure that their representatives to the ARM are aware of their feelings.

Newcastle upon Tyne

David A JeFFs

SIR,-I write to support Dr B M Goss (28 February, p 527) and fellow critics of mandatory specialist training.

At a time when finance is not available to fund necessary projects-for example, the present staff crisis in the Institute of Neurological Sciences in Glasgow-it is ridiculous that we as a profession should allow ourselves to be hoodwinked by spendthrift colleagues into wasting resources creating unnecessary further administrative posts to manage postgraduate training courses in general practice. It is well known to all experienced practising general practitioners that the art and science of general practice is learned in service, seeing the patients in the surgery and, probably more important, visiting them in their own homes. The aspirations of our academic leaders, often general practitioners themselves, seem to be to create a generation of pseudoconsultants who will be unwilling and untrained to tackle the majority of mixed medical/social problems seen in everyday practice and often during the now so-called unsocial hours. I suggest a ballot of all present serving principals in general practice to obtain their views on the need or otherwise for further expensive training before the young graduate becomes available to learn his chosen branch of medicine. If the young doctor wishes to follow a hospitalorientated career encourage him, but if he has the guts to enter general practice allow him to feel his chosen vocation before all his methods and ideas are more appropriate to a hospital situation. The day of the administrator's dream, "the plastic doctor," controlled by rules, regulations, and "advised" treatment, is not far from a reality, whereas the general practitioner should be relatively independent in thought and action and thus able to give a more complete service to his patient.

Further financial saving could, of course, be made by abolishing the need for attendance at postgraduate sessions as a requisite for obtaining a seniority allowance. There are many in the General Medical Services Committee and the BMA who consider such attendances important, but surely they must also accept that most doctors voluntarily update themselves by reading, attending lectures of choice, and having personal contact with consultant colleagues, usually concerning problems affecting their own patients. It remains GMSC policy not to require attendance at postgraduate meetings, yet some faceless non-medical negotiator was able to frustrate the profession by offering gold. It can still be argued that time spent with the patient is more important than time spent at an obligatory postgraduate session, few in required number as they may be.

D T HERRIOT

Rothesay,
Isle of Bute

\section{Consultants' ballot}

SIR,-As one of the consultants who contributed to the fiasco of the recent ballot I would like to have the opportunity of stating why I did not complete my paper.

I think question 6 was inept almost to the degree of being culpable in prejudicing the outcome of the ballot. Many are opposed to Lord Goodman's present proposals but surely this does not automatically mean that resignation is the only answer. Indeed I think few people would be prepared to resign unless over a very specific issue or series of issues. Lord Goodman's document is peppered with "reasonable" and "consultation" or "consultations" and it would be only after one found what the Government considered "reasonable" and what they intended to do after such "consultations" that the serious step of resignation would be considered by many.

G W H JARDINE

Regional Radiotherapy Centre,
Newcastle General Hospital,

Newcastle General Hosp
Newcastle upon Tyne

\section{Distinction awards}

SIR,-The statistics provided by Drs $\mathbf{P}$ Bruggen and $S$ Bourne in their examination of the distinction awards system (28 February, p 536) appear impressive but are, I think, devoid of meaning. General experience 